Studia Slavica Savariensia 2016. 1-2. 258-265

DOI: $10.17668 /$ SSS.2016.1-2.258

\author{
Kabyl Khalykov \\ (Almaty, Kazakhstan)
}

\title{
COMMUNICATION AND DIALOGUE OF THE ART TEXTS AS THE PHILOSOPHICAL PROBLEM
}

\begin{abstract}
In the article the role of interpretation of the art text is considered as aspect of understanding directed on the semantic content of texts. Any work of art anyway can be presented as objective existing text, possessing corresponding to material shell and structure. Integrative ideas sense will be born as a result of complex interaction figuratively-thematic building with external and internal form of the product. The Status of the work of art he gains only then, when to actualize and is perceived mortgaged contents in him.
\end{abstract}

Keywords: The art text, interpretation, phenomenology, hermeneutics, structurization of the text, a sign, clearing of codes, recipient, equivalence, similarity and distinction, synonyms and antonyms.

The problem of the text arising on crossing of linguistics, poetics, literary criticism, semiotics, starts to be discussed actively in humanitarian knowledge of the second half of the XX century. In the center of attention of polemics there was a problem of disclosing of meaning creation resources, or transformations in the sign macro formations, accompanied with acknowledgement or insufficiency of denotation as the basic model of value.

Interpretation of the text as composition in the studied problem is defined by different authors as: the psychological and cultural context of comprehension of meaning of the text (Diltey), result of interaction of a lot of ontological "layers", dynamic "phases" of expansion of the text (E. Husserl), infinite plurality of meanings contained in the composition anew formed in consciousness of the reader (F. Schelling), objective and subjective aspects of interpretation which define uniform process of understanding (G. Gadamer), opening of "existence in the world" through intrinsic moments of its organization (M. Heidegger), statement is an expression of idea (L. Vitgenshtein), a code in sphere of culture (R. Barthes), text as partially reversible, logic of behaviour put under doubt is actional code, "truth" is a code of a riddle (Z. Derrida), recomposition of the text structurization, clarifying of the reader's codes (P. Ricoeur).

Up-to-date works of art are also considered as the text. The art text is the carrier of conceptually loaded and value-oriented information, physical life of 
socially significant art idea. Outside of consumption the existence of the art text is defective; it exists only as potential composition.

The art text bears in itself an idea both in the plastic form and in the form of the ideas which have been not mediated by the image. The semantic center of the text can be displaced to the side of graphic, or not plastic, actually intellectual basis. It is impossible neither to reject nor to exaggerate any of these foundations in the text. So, in painting or sculpture the name comprises not plastic aspect of the content. In the literary text not plastic basis is always present alongside with the graphic basis. The latter is especially developed in the intellectual literature (Frisch, Dürrenmatt) and in symbolical images. Lessing has convincingly denied position «poetry is the speaking painting». There are three varieties of the text:

Scientific text (scientific work, report, message, lecture) does not demand interpretation: it is read by all means owing to unambiguity of meaning and defmiteness of meaning of scientific terms.

The practical, business text (letter, document, reporting) interpretation of which is caused by a communicative situation.

The art text, interpretation of which assumes: revealing of its analogy to the reality « by means of similarity », understanding of the context of the cultural tradition. The art text can have set of readings. But its polysemy (the amplitude of fluctuation around "the axis" of meaning) has its limits. Outside the extreme points of this amplitude reading becomes inadequate to the text. Perception of the art text is variant, but it contains invariant of these alternative versions and gives the steady program of art perception caused by its objective content (the art concept and value orientations). Characteristic features of the art text are: 1) completeness, impossibility of intervention from the outside; 2) changeability of meaning owing to changeability of historical and cultural context and owing to "dialogue" of the text with different reception groups with different personal consciousness; The recipient, perceiving the art text, is involved in the coauthorship which is giving rise to additional meaning; 3 ) formation of the field for the message as specific environment of art dialogue; 4) subject which is spoken about in the text, outside of this text does not exist; 5) the field of relations, on the basis of which there is a communication of the recipient with the art text, does not exist before perception of this text. The attitude to the text is recipient - interpretation (BOREV 2004: 169).

Sign is a minimal unit of the art text. The sign should be recognized, and the statement should be understandable. The system of statements forms the art text carrying the art concept, which is subject to interpretation and estimation.

The art text consists of artistic images, and the latter consist of signs. However, at each stage of transition to higher level (from a sign to the art statement, that is to the image, from system of images to the art text) there is a qualitative leap, removal of a previous level and occurrence and an increment of new meaning and new values of an art idea. The art text is the closed system.

The art text acquires the status of composition (the closed system becomes 
opened, socially functioning) in the process of social life. In the work of art symbolic and not symbolic are combined: signs form an art statement - an artistic image (not sign formation) by a qualitative leap; images form an art text (new leap) inclusion of which in social functioning transforms it into composition (a meta sign of art culture). Composition differs from the text that it is the functioning depressurized text which is making sense (the art concept) and subject value (value for mankind). The text becomes composition if does not wait for its hour in the writer's desk, does not collect dust on the shelf of a bookshop or in the storeroom of a museum, and socially functions, that is it is read by the public, finds the field of public opinion around itself. Composition is the form of life (MELVILLE 1995; WITTKOWER 1955: 109-124).

In the philosophical dictionary interpretation is defined as aspect of understanding directed on the semantic content of texts. And as a practice of extraction of meanings from texts it took place in antiquity ("allegorical" interpretation of texts), in the Middle Ages (bible exegetics), during an epoch of the Renaissance ("the criticism of the text", "grammar", lexicography). Regulations of the bible exegesis have received theoretical development in the romantic aesthetics: F. Schelling specified infinite plurality of the meanings contained in the composition and newly formed in consciousness of the reader (SCHELLING 1966). F. Schleiermacher gave categorial status to interpretation, he distinguished objective ("grammatical") and subjective ("psychological", or "technical") aspects of interpretation. Both aspects of interpretation define uniform process of understanding: Interpretation of the text from the subjective aspect assumes a certain notion about the author, but this representation can be formed only on the basis of some objective interpretation of his texts. "Grammatical" interpretation is carried out by means of comparative method - the comparative analysis of various meanings of this or that word with the purpose of an determination of its meaning in the given context. "Psychological" interpretations take place by the way of divination "guessing" a word meaning on the basis of studying that spectrum of its meanings which is specific to the given author (KEMEROV 1996: 222).

In Diltey's hermeneutics interpretation is reduced to comprehension of meaning of the text by means of its switching in a psychological and cultural context of the author and reconstruction of this context inside the interpreter's experience. Husserl proved that the preinstruction belongs to a phenomenon of consciousness, that is horizon consciousness (subsequently named by him "the vital world" and being essentially a context) which specifies on further attributes of the object, which are outside of the experience in the true meaning. It is "definitely a certain interpretation... We appear involved in variety which specifies on possible new perceptions.., and with obviousness it opens and carries out itself in a series of images and representations" (HUSSERL 1931). The phenomenological method starts from the fact that concrete integrity of the composition (and corresponding to it the act of direct, not dismembered perception) arises as result of interaction of a lot of ontological "layers", and 
also dynamic "phases" of expansion of the text. The goal of the interpreter is to explicit these layers and phases.

Interpretation within the limits of phenomenology of consciousness usurps independence outside its presented content and makes it actually unlimited. M. Heidegger, passing from phenomenology of consciousness to phenomenological hermeneutics, specified, that it is not a matter of tracing, supervision and examining of any point of egoism ("I"), but of conscious grasping of full opening of "existence in the world" through its intrinsic moments of its arrangement. Statements can be transferred further and retold (HEIDEGGER 1997). G. Gadamer transfers Heidegger's ontology of understanding into the theory of interpretation of the text as carrier of cultural tradition, asseverating unity of understanding, interpretation and "application". Understanding is always "interpreting", and interpretation is understanding", but once and for all the understanding is carried out as a result of "application", i.e. correlations of the content of the text with cogitative experience of the modern culture. The understanding, according to Gadamer, is aimed not at extraction of author's meaning, but at disclosing of the content of the "matter" shown in the text (GADAMER 1988).

According to L. Wittgenstein, the statement is an expression of thought. Thinking means operating with schemes, but idea is not the same as scheme because the idea does not require translation, and the scheme requires it. The scheme (without its interpretation) corresponds with the certain sentence transferring it into the statement. How is it possible to learn that someone has understood the scheme or the order? Wittgenstein believes that he can show his understanding only by means of its transformation into other symbols. Thus, understanding is transformation into other symbols or into action and consequently it is interfaced with interpretation (PILV 1996: 14).

There is also a positivistic understanding of interpretation which leads to an establishment and opening of the "objective" reasons of creation of the text. Both hermeneutics and semiology are opposed to historical and genetic approach. Within the limits of semiology there are two directions - structural and text analyses. The first direction aspires to develop uniform narrative model from all existing narrations by means of which it will be possible to analyze each concrete narration in terms of a deviation. The second direction considers any narration as the text which is understood as space where there is a process of formation of meanings. The goal of text analysis is not in the description of the narration structure, but in making mobile structurization of the text (changing according to reader's prospect and historical context) and to get into semantic volume of composition, in process of meaning acquiring. Hence, it is necessary to distinguish between structural and text analyses and not to consider them as mutually exclusive.

In hermeneutics interpretation is directed on disclosing of meaning of the text as the message, addressed to the possible reader, in semiotics it is directed on decoding of the code. R. Barthes relates a code to the area of culture: 
«Codes are the certain types of already visible, already read, already done; the code is the concrete form of this «already», constituting any letter». Barthes emphasizes, that in a classical narration there are two codes which support a vector orientation of structurization: they are an actional code (based on logical and temporal orderliness) and a code of a riddle (the question is concluded by the answer); in this way irreversibility of the story is created (BARTHES 1989). Derrida's deconstruction encroaches upon this principle, trying to make the text partially reversible, putting under doubt an opportunity of expressing logic of behaviour by actional code, and "truth" by a code of a riddle (DERRIDA 2000).

Tendency on overcoming of the opposition between hermeneutics and semiotics can be found out in Ricoeur's works, who considers "understanding" and "explanation" as components of the uniform process: the first one comprises recomposition of structurization of the text; the second one comprises clearing of codes of the reader participating in this process. In this connection the importance of a figure of the interpreter grows. The interpreter is the person who is carrying out interpretation. Any sign assumes presence of the interpreter. Perceptive type of the semiotic communication demands two separate interpreters: the sender and the addressee. Their distinction is that the first carries out operation of coding, and the second carries out operation of decoding. R. Jakobson allocated two major language factors. The first of these factors represents selection. It is based on equivalence, similarity and distinction, synonyms and antonyms. The second factor is a combination which adjusts construction of any sequence. It «is based on contiguity». At coding the sender carries out a choice of elements up to their combination in a single whole. Carrying out decoding operation, the addressee first of all should catch the whole; deep distinction between the listener's (reader's) status and the speaker's (writer's) status in speech dialogue (text) consists in this fact. The decoding partner of the speech act uses probabilistic decisions much more often than the coding partner. So, for the sender there is no problem of a homonymy for he knows its meaning whereas the addressee while he does not have support on a context struggles with a homonymy and has to resort to probabilistic tests of his decisions (RICOEUR 1995).

Written language (text) provides greater stability and availability of the message to the addressee who removed from the sender in time or distance. There is a sufficient distinction between the listener and the reader, consisting in transfer of speech sequence from time into space that weakens property of unidirectionality, characteristic for a speech stream. Listener synthesizes sequence when its elements have ceased to exist, and for the reader of a word are kept, and it can return from the subsequent parts of the message to previous ones. Internal speech unites the sender and the addressee into one person, and form ellipticity (of not completed expression) of intrapersonal communication cannot be reduced only to verbal signs. The mnemonic unit on a handkerchief, serving as a reminder on an important issue, is a typical example of the internal 
communications between the last and subsequent condition of one person.

Any work of art anyway can be presented as objective existing text, possessing corresponding to material shell and structure. On the strength of what particularities this text with firm interfacing and intercoupling can be open for interpreting? Exists single correct "canonical" reading music, literary, picturesque text? Discussing the delivered questions provokes artistic practice itself.

If, to example, match the essay Leskova "Lady Makbet Mcenskogo district", dramatic show, created on this base and of the same name of opera Shostakovich then in all three events will on hand be a different problemsolving nodes of this narrative and even different existence-semantics source positions. Consequently constantan's figuratively-thematic building not there is guarantor constantan's sense forms in different product and type art. In this one of the base positions to general theory art, fixing mismatch of the subject and ideas (the pathos) of the product.

Integrative ideas sense will be born as a result of complex interaction figuratively-thematic building with external and internal form of the product. To external form refer the voluptuous shell of the image, directly turned to perception (the colour, light, timbre of the sound, appearance of the actor, suit) i.e. language facilities of the miscellaneous type art. The Internal artistic form form the ways of the development, organizations and materializations of the language facilities (compositions acceptance in painting, literature, music, principles of the montage, polifonies, ways of the motion and declamations in scenic type art etc.) Meeting the different language facilities with one and same subject not simply differently arranges existence of this subject in art, but opens in this subject miscellaneous ontologics, profound forshortenings.

Is opera Bizet "Karmen" continuation same "existence to mythologies", which was a mortgaged of the same name short story Merime? Obviously that no, "thresholds of the place", generating base senses, are differently assigned stylestics literary and music text, of a plot move, rhythm, composition and other detail of the artistic language. Else, the greater amount of the questions will assign the artistic texts, which for its actualization need in public not only, but also in performer. This music and theatrics, where from experience, temperament, interpretation, cultural-history environment are greatly transformed source intension of the artistic text.

The Music text or text of the play, on the one hand, there is nothing else than physical object, impressions in note, typographical sign, keeping before time before time for regiment. The Status of the work of art he gains only then, when to actualize and is perceived mortgaged contents in him. In what degree this contents "is attached" to property base of the source author's text, but in what - openly for transformation? In performers type art meet, on the one hand, creator, supplying each tumbling of the text detailed note for performer. Other - opposite, leave the elbowroom for performer, do not specify his detailed instructions (Bach, Schubert). 
All like observations allow to confirm that as physical structure art does not exist: "If we consider product on the part of his untouchable reality and herewith nothing its not привнесем themselves, that turns out to be, - writes M. Heidegger, - that product emerges before us in the same way naturally as belongings. The Picture hungs on wall as hunting handgun or as hat. The Quartettes Beethoven to rest upon storehouse publishers as potatoes in cellar. All product possess this corporeality. Than were they without it?" Thereby, authentic existence of the artistic product - in his spiritual existence.

Developping this thesis, polish aestheticses Ingarden (1893-1970) is biased to interpret the way existence works of art as visibility. If it is impossible feel, touch this spiritual, psychic sense, signifies this air, which at all impossible define. "As, however, can exist something that is not neither psychic (conscious), nor physical, - moreover exist even then, when him nobody conciously does not concern with?... As possible to in most different performances audible was too most to every time was shown us same product in original, in its inherent look?" - asks Ingarden. Certainly, this impossible, moreover, folklore product, to example while lives, always s and never can be created once for ever - in absence of the author and reason his multiversions.

Else on thoughts of the E. Kants question about existence art most on itself turn out to be the deprived sense. His interpretation art as "practicability without purpose" expected the participation of the subject as integral figure of the artistic perception. Only through join intentions artistic text with real experience of the individual could take place nonsubjecting and actualization of the contents. Moreover, fact new itself and new approximation to already known product - an insscenes, interpretations, versions - a certificate ontological anexhaust, melting in him "reserve of the sense". Thence widespread judgement that present sense of the work of art there is collection all history sense, for which it gives the cause. Exactly ansolve, secret, riddle, metamorphosis of the artistic text allows each new epoch "in throw" in product its ontological problem.

In process of the history life of the products his cultural ambience, too being included in this artistic text; i.e. history interpreting the product, his artistic reputation creates the context, predestining the most further riverbed his nonsubjecting. The Researchers speculated on this problem, reconverge in that that symbology of the artistic product it is impossible identify neither with emotional condition his creator, nor with the same condition perceiving subject. The Product of the labour of the artist, when he completed, ceases to be its spiritual property and begins to express the sense, not always coinsiding with those, put the artist in it. 


\section{References}

BOREV 2004 = BOREV U.B. Aesthetics Series «Higher education». Rostov n/D: «Fenics», 2004.

KEMEROV 1996 = Modern philosophical dictionary. Under ed. d.f.s., prof. V.E. Кемеrov. 1996.

PILV 1996 = Philosophical ideas Lyudviga Vitgenshteyna. Moscow, 1996.

SCHELLING $1966=$ SCHELLING F.V.I. The Philosophy of Art [Tran. of the entr. article P.S. Popov and M.F. Ovsiannicov]. Moscow, 1966.

HUSSERL 1931 = HUSSERL E. Ideas: general introduction to pure phenomenology. London, 1931

MELVILLE $1995=$ Vision and textuality. Ed. by St. Melville, B. H. Reeding, Basitingstock, 1995.

WITTKOWER 1955 = WITTKOWER R. Interpretation of Visual Symbols in Art. Studies in Communication. London, 1955.

HEIDEGGER 1997 = HEIDEGGER M. Existence and time. Moscow, 1997.

GADAMER $1988=$ GADAMER H. The Truth and method. Moscow, 1988.

BARTHES 1989 = BARTHES R. Elected work. Moscow, 1989.

DERRIDA 2000 = Power and signification // Derrida ZH. Letter and difference. SPB: Академический проект, 2000.

RICOEUR $1995=$ RICOEUR P. Conflict interpretation. The Essays about hermeneutics. Moscow, 1995. 